\title{
Arthritis Induced in Rats by Cloned T Lymphocytes Responsive to Mycobacteria but Not to Collagen Type II
}

\author{
Joseph Holoshitz, Avraham Matitiau, and Irun R. Cohen \\ Department of Cell Biology, The Weizmann Institute of Science, \\ Rehovot, 76100, Israel; Department of Internal Medicine B, \\ Meir Hospital, Kfar Saba; Department of Pediatrics B, \\ Kaplan Hospital, Rehovot, 76100, Israel
}

bstract. We have been studying the pathogenesis of adjuvant arthritis in rats using a long-term cell line of $\mathrm{T}$ lymphocytes, the A2 line, which can induce polyarthritis and can also be used to vaccinate rats against adjuvant arthritis. Although line A2 was selected for its proliferative response to mycobacteria, it also responded to collagen type II. To elucidate its role of responsiveness to collagen type II and the relationship between arthritogenicity and vaccination, we cloned $\mathrm{A} 2$ and selected a subline $\mathrm{A} 2 \mathrm{~b}$. We now report that subline $\mathrm{A} 2 \mathrm{~b}$, which bore a marker of helper/delayed hypersensitivity $\mathrm{T}$ lymphocytes, was strongly arthritogenic, but could not vaccinate against arthritis. Moreover, A2b showed no response to collagen type II. Therefore, reactivity to collagen type II is not a requisite for arthritogenicity, and mediation of arthritis and vaccination can be distinct properties of different populations of $\mathrm{T}$ lymphocytes.

\section{Introduction}

Adjuvant arthritis (AA) ${ }^{1}$ is a model of arthritis that presents with a pathological picture similar to that seen in rheumatoid arthritis $(1,2)$. AA can be induced in susceptible strains of rats by a single intradermal injection of complete Freund's adjuvant (CFA) containing killed Mycobacterium tuberculosis (MT) in oil. Although AA is triggered by an immune response to mycobacterial antigens, the disease is transferable to naive recipient rats by inoculation of lymphoid cells obtained from affected

Dr. Cohen is the incumbent of the Mauerberger Professorial Chair in Immunology. 1983.

Received for publication 14 June 1983 and in revised form 1 September

1. Abbreviations used in this paper: AA, adjuvant arthritis; CFA, complete Freund's adjuvant; Con A, concanavalin A; MT, Mycobacterium tuberculosis; PPD, purified protein derivative.

J. Clin. Invest.

(C) The American Society for Clinical Investigation, Inc. 0021-9738/84/01/0211/05 \$1.00

Volume 73, January 1984, 211-215 rats (3); immune reactivity to joint antigens has also been detected (4). This suggests that AA may be an autoimmune disease and that a self-antigen responsible for expression of AA could exist in the joints of normal rats. However, the identity of the critical self-antigen and its relationship to mycobacterial antigens remain obscure. It has been suggested that $\mathrm{AA}$ is not an autoimmune disease but results from an attack against MT antigens disseminated in the tissues (5).

Autoimmune arthritis can be induced in rats by immunization to collagen type II, a collagen characteristic of joints (6). Based on the finding of antibody or $\mathrm{T}$ lymphocyte responses to collagen type II in rats with AA (7) and in humans with rheumatoid arthritis (8), it has been suggested that collagen type II may be a critical self-antigen in autoimmune arthritis (7).

To investigate the pathogenesis of AA we developed lines of $\mathrm{T}$ lymphocytes from the draining lymph nodes of Lewis rats immunized to CFA (9). Line A2, selected because of its proliferative response to whole MT, could induce polyarthritis upon intravenous injection into irradiated Lewis rats. Cells of line A2 could also be used to vaccinate rats against subsequent attempts to induce AA by active immunization to CFA. We observed that in addition to responding strongly to MT, line A2 proliferated in vitro to a relatively slight but significant degree to collagen type II. Hence it was conceivable that some MT antigens might cross-react with self-collagen type II and that induction of arthritis and/or vaccination against AA might be the property of line cells reactive to collagen type II (9).

The present experiments were done to test this hypothesis. Accordingly, we prepared a cloned subline, A2b, that was found to be more strongly arthritogenic than the parent A2 line. However, unlike the $A 2$ line, the $A 2 b$ subline could not induce resistance to AA. Moreover, subline $\mathrm{A} 2 \mathrm{~b}$ responded in vitro strongly to MT antigens but not at all to collagen type II. Thus, arthritogenicity and vaccination may be produced by separate populations of cells, and reactivity to collagen type II is not required to induce autoimmune arthritis. Finally, we were able to transfer arthritis with line cells that had been activated by the mitogen concanavalin A (Con A) in place of MT. This argues against the notion that disseminated $\mathrm{MT}$ antigens are the requisite target for $\mathrm{AA}$ and suggests that a target self-antigen exists in the joints. 


\section{Methods}

Rats. Inbred Lewis rats were obtained from the Animal Breeding Center of The Weizmann Institute of Science. Rats were used at 2-3 mo of age and were matched for age and sex in each experiment.

Antigens. Heat-killed $M$. tuberculosis $\mathrm{H}_{37} \mathrm{R}_{\mathrm{a}}$ was purchased from Difco Laboratories (Detroit, MI). Purified protein derivative (PPD) of mycobacterium was purchased from Staten Serum Institute (Copenhagen, Denmark) and Con A from Bio-Yeda (Rehovot, Israel). Purified rat type II collagen was kindly donated by Dr. E. J. Miller of the University of Alabama Medical Center, Birmingham. Rat type I collagen was prepared from rat tail tendons and donated by Dr. D. Duksin of the Department of Biophysics of The Weizmann Institute (10).

Culture medium. All cell cultures used Dulbecco's modification of Eagle's medium (Grand Island Biological Co. (Gibco), Grand Island, New York). Medium used for proliferation assay, for restimulation, and for cloning (proliferation medium) was supplemented with $1 \mathrm{mM}$ glutamine (Bio-Lab, Jerusalem, Israel), 2-mercaptoethanol $\left(5 \times 10^{-5} \mathrm{M}\right)$, gentamycin $(40 \mu \mathrm{g} / \mathrm{ml})$, and $1 \%$ fresh autologous rat serum. The medium used to maintain the propagate cell lines and clones in long-term culture (propagation medium) was the proliferation medium supplemented with $15 \%$ (vol/vol) of supernatant of Con A-stimulated lymphocytes as a source of $\mathrm{T}$ cell growth factor (11), 10\% horse serum (Gibco), $1 \mathrm{mM}$ sodium pyruvate, and nonessential amino acids (Bio-Lab).

Induction of active $A A$. To induce active $\mathrm{AA}$, rats were inoculated intradermally at the base of the tail with $0.1 \mathrm{ml}$ of CFA containing 10 $\mathrm{mg} / \mathrm{ml} \mathrm{MT}$ in incomplete Freund's adjuvant (Difco Laboratories). The system described by Trentham et al. (6) was used to assess severity of arthritis. Each paw was graded from 0 to 4 based on erythema, swelling, and deformity of the joint. The highest score achievable was 16 . The clinical diagnosis of AA was confirmed by histologic examination of the joints of selected rats (1).

Maintenance and cloning of line $A 2$. Line A2 reactive to MT was isolated from rats immunized with CFA. On day 9 the draining lymph nodes were removed, and a $\mathrm{T}$ cell line reactive to $\mathrm{MT}$ was generated and maintained as we have described (9). The limiting dilution technique was employed to clone $\mathrm{A} 2$. The line cells were restimulated in vitro by incubating them with MT in the presence of accessory cells, as described below, for $3 \mathrm{~d}$. On the third day, the lymphoblasts were transferred into propagation medium for another 7-d period. On the 10th day, the cells were collected, washed, counted three times, and vigorously mixed. Cells were seeded at 0.1 cells/well in the presence of irradiated $(1,500 \mathrm{rad})$ thymus cells $\left(2 \times 10^{7} / \mathrm{ml}\right)$ and MT $(10 \mu \mathrm{g} / \mathrm{ml})$ into $96-w e l l$ microtiter plates in $100 \mu \mathrm{l}$ of proliferation medium per well. Wells were checked for cell growth from the 6 th to the 14th day after cloning. Plating efficiency was $60 \%$. Cloned cells were expanded in propagation medium in 200 $\mu \mathrm{l}$ wells and then in $2-, 6-$, and, finally, $10-\mathrm{ml}$ plates at a concentration of 2-4 $\times 10^{5}$ cells $/ \mathrm{ml}$. Cultures were transferred every 3-4 d. Once every 2-4 wk, the line cells were restimulated by incubation with MT and accessory cells for $3 \mathrm{~d}$ (see below), and then transferred back into propagation medium. Cloned subline $A 2 b$, which is the subject of this report, was propagated in this manner for $6 \mathrm{wk}$ before study of its proliferative response to antigens or its ability to mediate $\mathrm{AA}$ or induce resistance.

Restimulation of line cells. Cells $\left(2 \times 10^{5} / \mathrm{ml}\right)$ of line $\mathrm{A} 2$ or subline A2b were restimulated by incubation for $3 \mathrm{~d}$ with $10 \mu \mathrm{g} / \mathrm{ml}$ of MT or $2.5 \mu \mathrm{g} / \mathrm{ml}$ of Con A in the presence of syngeneic irradiated (1,500 rad) thymus cells $\left(15 \times 10^{6} / \mathrm{ml}\right)$ as accessory cells in the proliferation medium. After $3 \mathrm{~d}$ the lymphoblasts were collected, washed twice in phosphatebuffered saline (PBS), and were either transferred into propagation medium or used for in vivo or in vitro studies. By this time most of the irradiated thymus cells had died and disintegrated.
Analysis of membrane markers. Monoclonal antibodies were donated by Dr. A. F. Williams from the MRC-Cellular Immunology Unit, Sir William Dunn School of Pathology, Oxford, England, and included: Clone W3/13, a mouse antibody against rat T lymphocytes; Clone W3/ 25 , a mouse antibody against rat $T$ helper cells; Clone OX8, a mouse antibody against rat $T$ cells (nonhelper subset); and Clone $O X 3$, a mouse antibody against rat Ig that binds to rat $B$ lymphocytes. Fluoresceinated rabbit anti-mouse Ig antisera were obtained from Nordic Immunological Laboratories, Tilburg, The Netherlands.

Fluorescence analysis was performed using the Becton Dickinson FACS analyzer (Becton Dickinson \& Co., Orangeburg, NY). Viable line cells $\left(2.5 \times 10^{6}\right)$ or normal thymus cells in $0.1 \mathrm{ml}$ of PBS were incubated for $30 \mathrm{~min}$ at $4^{\circ} \mathrm{C}$ with $20 \mu \mathrm{l}$ of the monoclonal antibody $(20 \mu \mathrm{g} / \mathrm{ml})$. The cells were washed twice and incubated for $30 \mathrm{~min}$ at $4^{\circ} \mathrm{C}$ with 20 $\mu l$ of fluoresceinated rabbit anti-mouse Ig. After further washing, the cells were resuspended in $1 \mathrm{ml}$ of $0.2 \%$ sodium azide-PBS, kept in ice, and analyzed for their relative scattering and fluorescence using the FACS analyzer. The frequency and fluorescence profile of the stained cells were determined by exciting the cells with $48.5-\mathrm{nm}$ line, and the fluorescent signals were detected with a photomultiplier tube. At least 10,000 viable cells (as gated by the scatter analysis) were analyzed for fluorescence intensity at different gains.

Proliferative responses. Line cells were incubated in flat-bottomed microtiter plates in quadruplicate wells. Each well contained $2.5 \times 10^{4}$ cells plus $2 \times 10^{6}$ accessory cells in the form of irradiated (1,500 rad) syngeneic thymus cells in $0.2 \mathrm{ml}$ of proliferation medium with antigens in the optimal concentrations determined by dose-response experiments: $\mathrm{MT}, 10 \mu \mathrm{g} / \mathrm{ml}$; PPD, $25 \mu \mathrm{g} / \mathrm{ml}$; Con A, $2.5 \mu \mathrm{g} / \mathrm{ml}$; rat type I collagen, $50 \mu \mathrm{g} / \mathrm{ml}$; and rat type II collagen, $50 \mu \mathrm{g} / \mathrm{ml}$. After $24 \mathrm{~h}$ of incubation, each well was pulsed with $1 \mu \mathrm{Ci}$ of $\left[{ }^{3} \mathrm{H}\right]$ thymidine (specific activity 10 $\mathrm{Ci} / \mathrm{mmol}$; Nuclear Research, Negev, Israel) for $18 \mathrm{~h}$. The cultures were then harvested on fiberglass filters and the incorporation of thymidine was measured using a liquid scintillation counter. The proliferative response was expressed as cpm (mean cpm of test cultures minus mean cpm of control cultures).

AA mediated by cell lines. Before being inoculated, line cells were restimulated with MT or Con A in the presence of accessory cells for $3 \mathrm{~d}$. The lymphoblasts were collected, washed twice in PBS, and 2 $\times 10^{7}$ cells in $1 \mathrm{ml}$ of $\mathrm{PBS}$ were injected into the tail vein of nonirradiated Lewis rats, or Lewis rats that had been irradiated $2 \mathrm{~h}$ earlier with 750 rad by a ${ }^{60} \mathrm{Co}$ gamma ray source (GB $150 \mathrm{~A}$, Atomic Energy of Canada Ltd., Commercial Projects, Ottawa, Ontario, Canada). The recipient rats were observed daily for clinical arthritis and were scored as above.

\section{Results}

Line $A 2$ and subline $A 2 b$ have the $T$ helper phenotype. Fig. 1 shows an analysis of surface markers on subline $A 2 b$ and on normal thymocytes. The thymocytes were positive for a general rat $\mathrm{T}$ lymphocyte marker (W3/13), a $\mathrm{T}$ helper lymphocyte marker (W3/25), and a nonhelper marker (OX8), and were negative for a B lymphocyte marker (OX3). Clone A2b, in contrast, was negative for the OX8 marker as well as for the OX3 marker. It was positive for the other $T$ markers (W3/13 and $\mathrm{W} 3 / 25$ ), as was the parent A2 line (not shown). Thus the $\mathrm{A} 2$ line and its $\mathrm{A} 2 \mathrm{~b}$ clone bore the phenotypic markers of helper/ delayed hypersensitivity $\mathrm{T}$ lymphocytes.

Subline A2b does not respond to collagen type II. Table I tabulates the proliferative response of the parent $A 2$ line and 

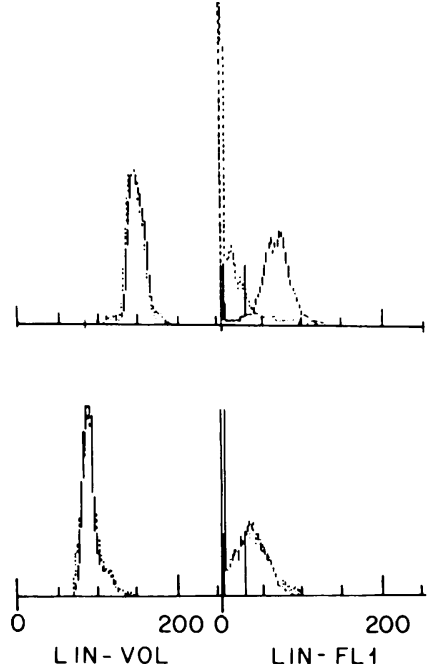

Figure 1. Binding of

monoclonal antibodies specific for rat $T$ lymphocytes. Scatter (left) and fluorescence (right) distribution profiles of normal thymus (lower) and cloned subline A2b cells (upper) that were stained with monoclonal antibodies specific for markers of helper rat $\mathrm{T}$ lymphocytes (W3/25; broken line) or nonhelper $\mathrm{T}$ lymphocytes (OX8; dotted line). Note that the thymocytes were smaller than the $A 2 b$ cells and were positive for both markers while the $\mathrm{A} 2 \mathrm{~b}$ cells were positive for the W3/25 marker and negative for the $0 \times 8$ marker. Both populations were positive for the general T lymphocyte marker (W3/13) and negative for a B lymphocyte marker (OX3; not shown). The $\mathrm{A} 2$ line was identical in staining to the $\mathrm{A} 2 \mathrm{~b}$ subline (not shown).

its cloned subline A2b to whole MT, collagens type I and II, PPD, and Con A. Both cell populations showed the same general pattern of reactivity except that $A 2 b$, unlike $A 2$, had no detectable response to collagen type II. Thus, line A2 and subline $\mathrm{A} 2 \mathrm{~b}$ provided us with reagents to correlate arthritogenicity with responsiveness to collagen type II.

Subline A2b is arthritogenic. Table II shows the results of inoculating Lewis rats intravenously with $2 \times 10^{7}$ cells of the parent A2 line or cloned subline A2b. As we reported earlier, arthritis was inducible only in recipient rats that had been irradiated before inoculation (9). It can be seen that subline $A 2 b$ was relatively more arthritogenic than the $\mathrm{A} 2$ parent line because it induced a more severe arthritis that began somewhat earlier and lasted longer. The more marked arthritogenicity of $A 2 b$ was evident in each of four additional experiments. Thus, the ability to induce autoimmune arthritis was not correlated with reactivity to collagen type II expressed in the in vitro proliferative response.

Table I. Proliferative Responses of Line A2 and Cloned Subline $A 2 b$

\begin{tabular}{lllllll}
\hline & \multicolumn{5}{c}{ Proliferative response } \\
\cline { 2 - 6 } Cells & MT & Collagen II & Collagen I & PPD & Con A & Background \\
\hline & & \multicolumn{5}{c}{$\Delta c p m \times 10^{-3}$} \\
A2 & 75 & 12 & 0 & 56 & 104 & 1.4 \\
A2b & 56 & 0 & 0 & 55 & 70 & 0.9
\end{tabular}

$\left[{ }^{3} \mathrm{H}\right]$ Thymidine incorporation of anti-MT line A2 and cloned subline A2b cells $\left(2.5 \times 10^{4} /\right.$ well $)$ stimulated in vitro with various antigens in the presence of irradiated $(1,500 \mathrm{rad})$ syngeneic thymocytes $\left(2 \times 10^{6}\right)$ well) as accessory cells.
Table II. Arthritis Mediated by Line A2 and Cloned Subline A2b

\begin{tabular}{lllllll}
\hline \multicolumn{2}{c}{ Cells } & & \multicolumn{4}{c}{ Arthritis } \\
\cline { 5 - 7 } Line & Activation & $\begin{array}{l}\text { Rats } \\
\text { irradiated } \\
\text { (750 rad) }\end{array}$ & $\begin{array}{l}\text { \% Incidence } \\
\text { (No. rats) }\end{array}$ & $\begin{array}{l}\text { Mean day } \\
\text { of onset }\end{array}$ & Duration & $\begin{array}{l}\text { Arthritis } \\
\text { score }\end{array}$ \\
\hline & & & & & $d$ & \\
A2 & MT & No & $0(19)$ & - & - & - \\
& MT & Yes & $100(24)$ & 8.0 & 18.0 & 4.5 \\
& Con A & Yes & $100(6)$ & 8.0 & 17.0 & 5.0 \\
A2b & MT & No & $0(22)$ & - & - & - \\
& MT & Yes & $100(18)$ & $5.0^{*}$ & $31.0^{*}$ & $6.8^{*}$ \\
\hline
\end{tabular}

Line $\mathrm{A} 2$ or cloned subline $\mathrm{A} 2 \mathrm{~b}$ cells $\left(2 \times 10^{7} / \mathrm{rat}\right)$ were injected intravenously into either naive or irradiated ( $750 \mathrm{rad}$ ) Lewis rats after activation using either MT or Con A. The lines had been maintained in propagation medium and transferred every $3 \mathrm{~d}$ for $4 \mathrm{wk}$ before activation. Rats were checked daily and the arthritis was scored as described in Methods. The standard deviation of each determination was $<12 \%$ of the mean.

$* P<0.01$ compared with values for $\mathrm{A} 2$

Arthritogenic potential is activated by Con A. As active AA is induced by immunization to MT, the target of immune attack might conceivably be bona fide MT antigens disseminated in the joints and not a cross-reactive self-antigen (5). According to this view, the transfer of AA by T lymphocyte lines activated by incubation with MT organisms could be explained by inadvertent transfer of minute amounts of MT antigens along with the line cells. We therefore undertook to induce arthritis with line cells that were not cultured with MT. We found previously that it was possible to activate the functional programs of line cells mediating autoimmune encephalomyelitis or autoimmune thyroiditis by incubation with Con A rather than specific antigen $(12,13)$. Table II shows that Con A also activated the arthritogenic potential of line A2 to the same extent as did incubation of the cells with MT. The last contact of the A2 line cells with MT was 4 wk before their activation, an interval marked by seven cell transfers, each involving a change of medium. Therefore, proximate contact with MT antigens and presumably their cotransfer with the line cells was not required for induction of arthritis.

Subline $A 2 b$ does not induce resistance to $A A$. To test whether cloned subline $\mathrm{A} 2 \mathrm{~b}$ could be used to generate resistance to AA we inoculated rats, irradiated or not, with $2 \times 10^{7}$ cells of $A 2$ or $A 2 b$ and induced $A A$ by active immunization with CFA 35 d later (Table III). Control rats that had not received line cells developed AA with about the same incidence (8090\%) and degree of severity (arthritis score 8-9), whether or not they had been irradiated $35 \mathrm{~d}$ earlier. In contrast, rats inoculated with line A2 were markedly resistant to AA. Vaccination against AA was evident in rats that had not been irradiated and therefore had not suffered passive arthritis mediated by the line cells. Resistance was also acquired by the irradiated rats that had suffered arthritis. However, rats that had been inoculated with cloned subline $\mathrm{A} 2 \mathrm{~b}$ showed no resistance to $\mathrm{AA}$, whether or not they had been irradiated and had suffered passive arthritis. 
Table III. Resistance to AA Induced by Line Cells

\begin{tabular}{|c|c|c|c|c|c|c|}
\hline \multirow[b]{2}{*}{$\begin{array}{l}\text { Transferred } \\
\text { cells }\left(2 \times 10^{7}\right)\end{array}$} & \multirow[b]{2}{*}{$\begin{array}{l}\text { Recipient } \\
\text { rats irradiated } \\
(750 \mathrm{rad})\end{array}$} & \multirow[b]{2}{*}{$\begin{array}{l}\text { Development of } \\
\text { line-mediated } \\
\text { arthritis }\end{array}$} & \multicolumn{4}{|c|}{$\begin{array}{l}\text { Resistance assayed by AA induced by CFA } 350 \\
\text { after line transfer }\end{array}$} \\
\hline & & & $\begin{array}{l}\% \text { incidence } \\
\text { (No. rats) }\end{array}$ & $\begin{array}{l}\text { Mean day } \\
\text { of onset }\end{array}$ & Duration & $\begin{array}{l}\text { Arthritis } \\
\text { score }\end{array}$ \\
\hline & & & & & $d$ & \\
\hline \multirow[t]{2}{*}{ None } & No & No & $89(76)$ & 12.9 & 56 & 8.9 \\
\hline & Yes & No & $81(42)$ & 13.6 & 55 & 8.6 \\
\hline \multirow[t]{2}{*}{ A2 } & No & No & $0(69)$ & - & - & - \\
\hline & Yes & Yes & $0(38)$ & - & - & - \\
\hline \multirow[t]{2}{*}{$\mathrm{A} 2 \mathrm{~b}$} & No & No & $91(22)$ & 13.7 & 53 & 8.4 \\
\hline & Yes & Yes & $93(14)$ & 13.9 & 54 & 8.5 \\
\hline
\end{tabular}

Irradiated (750 rad) or nonirradiated Lewis rats were injected intravenously with $2 \times 10^{7}$ cells of line A2 or cloned subline A2b. $35 \mathrm{~d}$ later active AA was induced by an intradermal injection of CFA to assay for acquired resistance to AA in irradiated rats developing linemediated arthritis or in unirradiated rats that did not suffer from arthritis. Control groups consisting of irradiated or nonirradiated rats were injected with CFA $35 \mathrm{~d}$ after irradiation. Rats were checked and scored for arthritis as described in Methods.

\section{Discussion}

Although the A2b cloned subline was similar to its parental A2 line in being able to cause arthritis, it differed from line $A 2$ in that it could not respond in vitro to collagen type II or endow rats with resistance to AA. In other words, the arthritogenicity of a population of $\mathrm{T}$ lymphocytes may be independent of its capacity to respond to collagen type II and dissociated from its ability to vaccinate. This conclusion would remain valid even if $\mathrm{A} 2 \mathrm{~b}$ was composed of a genetically heterogeneous mixture of $\mathrm{T}$ lymphocytes, a situation that could have arisen from the unlikely circumstance of more than one A2 line cell landing in a single well during cloning or from undetected genetic divergence occurring in the $\mathrm{A} 2 \mathrm{~b}$ population after cloning.

Thus, our results argue against the hypothesis that collagen type II is the critical self-antigen in AA. Additional evidence against a role for collagen type II in AA derives from the finding that rats that had been rendered resistant to AA by pretreatment with low doses of CFA were still susceptible to arthritis induced by immunization to collagen type II (14).

Given that collagen type II is not the target of autoimmune attack in AA, is there any other antigen whose presence in the joints could explain AA? An observation that AA could not be transferred with thoracic duct cells unless mycobacteria were added was interpreted as illustrating the need for MT antigens to serve as targets in the recipient rats (5). Thus, MT disseminated to the joints rather than an endogenous joint antigen might be the target of attack in AA. However, the MT might have been needed to activate the thoracic duct lymphocytes rather than to provide the joints with target MT antigens. This idea is supported by the observation that spleen cells activated with Con A could transfer AA (15). Our finding that A2 line cells could induce arthritis subsequent to activation by Con $\mathrm{A}$ as well as by MT argues against an absolute requirement for MT in the cell inoculum. Therefore, the autoimmune hypothesis seems the more attractive because the presence of bacterial antigens in the joints of the recipient rats under such circumstances seems doubtful. We hope that the response of $\mathrm{A} 2 \mathrm{~b}$ to various antigenic fractions of MT will help identify the cross-reactive antigenic determinant and resolve the question.

The pathology of the arthritis induced by $A 2$ or $A 2 b$ will be reported in detail elsewhere. In general the lesion appeared similar to those seen in active AA or in rheumatoid arthritis and were marked by heavy mononuclear infiltration of the synovium, formation of pannus, and erosion of articular cartilage. The arthritogenic T lymphocyte lines bore the W13/25 marker of helper/delayed hypersensitivity $\mathrm{T}$ cells. It is unlikely that recipient rats irradiated by 750 rad could have contributed the B lymphocytes needed for formation of possibly arthritogenic antibodies (16), which suggests that the line cells might induce arthritis by a delayed hypersensitivity reaction triggered by a cross-reactive self-antigen.

The mechanism of vaccination against $A A$ induced by the A2 line cells remains to be clarified. The arthritogenic $A 2 b$ subline, in contrast to the A2 line, failed to induce resistance even in rats in which it had caused arthritis. Thus, resistance was associated with the administration of a specific population of $\mathrm{T}$ lymphocytes and did not result from rats merely having suffered and spontaneously recovered from passive arthritis. In other words, the signal that induced protection was borne by the $T$ lymphocyte line cells, and was not inherent in the arthritic joint. As A2 and A2b differ in the antigenic specificities they recognize, it is conceivable that resistance to AA was induced by immunity to the antiself receptors of the A2 line cells. This 
type of antiidiotypic immunity is also compatible with the nature of the specific resistance induced by lines of $T$ lymphocytes against autoimmune encephalomyelitis in rats and against autoimmune thyroiditis in mice $(13,17,18)$. If indeed vaccination is mediated by antireceptor or antiidiotypic immunity, it is conceivable that the cloned $\mathrm{A} 2 \mathrm{~b}$ subline failed to protect because its receptor, while sufficient to cause disease, did not immunize the recipient rats against the entire array of autoimmune idiotypes generated during active AA. In contrast, the A2 line might have been an effective vaccine because of its idiotypic heterogeneity.

The reactivity of line A2 to collagen type II was relatively modest but significant. One could speculate therefore that cells recognizing collagen type II might have some role in vaccination against active AA (9). However, other interpretations are conceivable and these hypotheses must be tested with suitable antiidiotypic reagents and clones specific for collagen type II. In any event, the results clearly prove that disease and vaccination can be dissociated properties of autoimmune $T$ lymphocytes.

\section{Acknowledgments}

This work was supported by National Institutes of Health grant No. AM-32192. Dr. Holoshitz was supported by the Schrieber Fund, TelAviv University and by the Israel Ministry of Health.

\section{References}

1. Pearson, C. M. 1956. Development of arthritis, periarthritis and periostitis in rats given adjuvant. Proc. Soc. Exp. Biol. Med. 91:95-101.

2. Pearson, C. M. 1964. Experimental models in rheumatoid disease. Arthritis Rheum. 7:80-86.

3. Pearson, C. M., and F. D. Wood. 1964. Passive transfer of adjuvant arthritis by lymph node or spleen cells. J. Exp. Med. 120:547-560.

4. Berry, H., D. A. Willoughby, and J. P. Giroud. 1973. Evidence for an endogenous antigen in the adjuvant arthritic rat. J. Pathol. 111:229238.

5. Quagliata, F., and J. M. Phillips-Quagliata. 1972. Competence of thoracic duct cells to the transfer of adjuvant disease and delayed hypersensitivity. Evidence that mycobacterial components are required for successful transfer of the disease. Cell. Immunol. 3:78-87.
6. Trentham, D. E., A. S. Townes, and A. H. Kang. 1977. Autoimmunity to type II collagen: an experimental model of arthritis. J. Exp. Med. 146:857-868.

7. Trentham, D. E., W. J. McCune, P. Susman, and J. R. David. 1980. Autoimmunity to collagen in adjuvant arthritis of rats. J. Clin. Invest. 66:1109-1117.

8. Trentham, D. E., R. A. Dynesias, R. E. Rocklin, and J. R. David. 1978. Cellular sensitivity to collagen in rheumatoid arthritis. N. Engl. J. Med. 299:327-333.

9. Holoshitz, J., Y. Naparstek, A. Ben-Nun, and I. R. Cohen. 1983. Lines of $\mathrm{T}$ lymphocytes induce or vaccinate against autoimmune arthritis. Science (Wash. DC). 219:56-58.

10. Duksin, D., A. Maoz, and S. Fuchs. 1975. Differential cytotoxicity activity of anticollagen serum on rat osteoblasts and fibroblasts in tissue culture. Cell. 5:83-86.

11. Ben-Nun, A., and I. R. Cohen. 1982. Experimental autoimmune encephalomyelitis (EAE) mediated by $T$ cell lines: process of selection of lines and characterization of the cells. J. Immunol. 129:303-308.

12. Naparstek, Y., A. Ben-Nun, J. Holoshitz, T. Reshef, A. Frenkel, M. Rosenberg, and I. R. Cohen. 1983. T lymphocyte lines producing or vaccinating against autoimmune encephalomyelitis (EAE): functional activation induces PNA receptors and accumulation in the brain and thymus of line cells. Eur. J. Immunol. 13:418-423.

13. Maron, R., R. Zerubavel, A. Freidman, and I. R. Cohen. T lymphocyte line specific for thyroglobulin produces or vaccinates against autoimmune thyroiditis in mice. $\mathrm{J}$. Immunol. In press.

14. Iizuka, Y., and Y. H. Chang. 1982. Adjuvant polyarthritis. VII. The role of type II collagen in pathogenesis. Arthritis Rheum. 25:13251332.

15. Taurog, J. D., G. P. Sandberg, and M. L. Mahowald. 1983. The cellular basis of adjuvant arthritis. I. Enhancement of cell-mediated passive transfer by Concanavalin $A$ and by immunosuppressive treatment of the recipient. Cell. Immunol. 75:271-282.

16. Stuart, J. M., M. A. Cremer, A. S. Townes, and A. H. Kang. 1982. Type II collagen-induced arthritis in rats. Passive transfer with serum and evidence that IgG anticollagen antibodies can cause arthritis. J. Exp, Med. 155:1-16.

17. Beb-Nun, A., H. Wekerle, and I. R. Cohen. 1981. Vaccination against autoimmune encephalomyelitis with T-lymphocyte line cells reactive against myelin basic protein. Nature (Lond.). 292:60-61.

18. Cohen, I. R., A. Ben-Nun, J. Holoshitz, R. Maron, and R. Zerubavel. 1983. Vaccination against autoimmune disease using lines of autoimmune T lymphocytes. Immunol. Today. 4:227-230. 